\title{
Current position of psychiatry in UK foundation schools ${ }^{\dagger}$
}

\author{
John Lowe, ${ }^{1}$ Gianetta Rands ${ }^{2,3}$
}

The Psychiatrist (2012), 36, 65-68, doi: 10.1192/pb.bp.109.026419

${ }^{1}$ St Charles Hospital, London; ${ }^{2}$ Camden and Islington NSH Foundation Trust;

${ }^{3}$ University College London

Correspondence to John Lowe (jlowe@nhs.net)

First received 10 Aug 2009, final revision 22 Aug 2010, accepted 3 Dec 2010

\begin{abstract}
Aims and method We report an audit of the provision of psychiatric postgraduate education within the foundation programme and psychiatry specialty programmes in the UK. Our primary measure was the number of foundation posts in psychiatry. Our audit standard was that all foundation doctors should receive programmed training in psychiatry via a psychiatry foundation post.
\end{abstract}

Results We found a total of 413 foundation posts in psychiatry in 21 out of 22 foundation schools in England. This figure is only a fifth of that required to meet the audit standard. There is training capacity for 500 core trainees and 460 higher trainees in psychiatry per year. Currently, $13.6 \%$ of specialists other than general practitioners on the General Medical Council registers are psychiatrists.

Clinical implications The provision of programmed postgraduate training in psychiatry in UK foundation schools is inadequate. The training needs of all doctors, the mental healthcare needs of all patients, and recruitment to psychiatry are all likely to suffer as a consequence.

Declaration of interest None.
Modernising Medical Careers ${ }^{1}$ promised a 'new dawn' for medical training in the UK. This included a major expansion and remodelling of the old pre-registration house officer year into a 2-year competency-based foundation programme delivered by the newly formed foundation schools. The purpose of the foundation programme was to deliver a modern and safe platform of generic training for all postgraduate doctors preparatory to clinical specialisation. The programme was based on a foundation curriculum ${ }^{2}$ in which psychiatric competencies were comprehensively covered. At the outset, optimism was expressed that there may be opportunities for 'Cinderella' specialties such as psychiatry to enhance their representation at postgraduate level. ${ }^{3,4}$ Anecdotally, where foundation posts in psychiatry have been established the feedback has been positive. ${ }^{5}$

Five years after the launch of the foundation programme we report a national audit of the establishment of psychiatry in foundation schools. As our primary measure of success we took the number of training posts in psychiatry in the foundation schools. Our target or standard of success was that every foundation doctor should be able to access programmed work-based training in psychiatry delivered via a psychiatric foundation training post.

\section{Method}

Between late 2008 and early 2009, using a Royal College of Psychiatrists' database, we sampled by postal questionnaire

See commentary, pp. 69-70, this issue. the entire population of foundation directors and managers in the foundation schools in England (at the time the database did not include Scotland, Wales or Northern Ireland).

Each school was asked to provide current information on the number of foundation year 1 (FY1) and year 2 (FY2) posts, number of FY1 and FY2 posts in psychiatry, number of foundation doctors in receipt of 'tasters' in psychiatry and number of foundation doctors progressing to a specialist training in psychiatry. Simultaneously, we also surveyed all 13 heads of psychiatry specialty schools in England, sending them a questionnaire (Box 1). Three reminders were sent over 6 weeks.

We then compared these data with information about numbers of doctors on specialist registers obtained through a freedom of information request to the General Medical Council (GMC). We did not prospectively define terms but in analysing the data and throughout this paper we used the definitions from Modernising Medical Careers and The Gold Guide $^{6}$ as summarised in the Appendix.

\section{Results}

Responses were obtained for 21 out of 22 foundation schools in England, with data for one school in Oxford (approximately 450 posts) missing, in the context of a reorganisation of the postgraduate training in NHS South Central Strategic Health Authority. We found a total of 413 foundation posts in psychiatry or $3.5 \%$ out of a total of 11668 posts. There were $121 \mathrm{FY} 1$ posts $(2.0 \%)$ and $292 \mathrm{FY} 2$ 


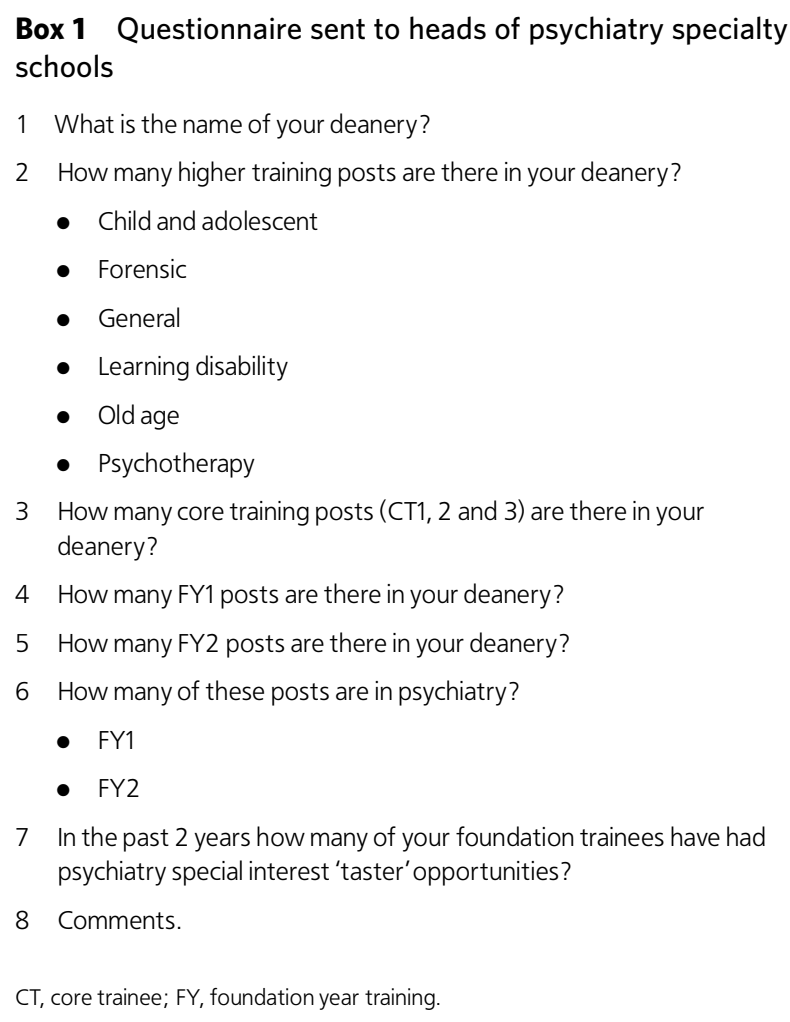

3 How many core training posts (CT1, 2 and 3) are there in your deanery?

4 How many FY1 posts are there in your deanery?

5 How many FY2 posts are there in your deanery?

6 How many of these posts are in psychiatry?

- $\mathrm{FY} 1$

- $\mathrm{FY} 2$

7 In the past 2 years how many of your foundation trainees have had psychiatry special interest 'taster' opportunities?

8 Comments.

$C T$, core trainee; FY, foundation year training.

posts $(5.1 \%)$. The distribution across the different foundation schools is shown in Table 1. Responses to the specific items relating to foundation tasters and progression to psychiatry were sparse and on the whole anecdotal.

All 13 heads of schools of psychiatry in England returned their questionnaires. We found 1498 core training posts and 1378 higher training posts. As both core and higher training programmes are 3 years long, we estimated that the training capacity for schools of psychiatry in England is about 500 doctors per year for core training and 460 doctors per year for higher training. This represents a ratio of 1 core post to 0.92 higher posts (Table 2).

The percentages of higher training posts in the six subspecialties were: child and adolescent $16 \%$, forensic $9 \%$, general psychiatry $48 \%$, learning disability $6 \%$, old age $17 \%$, and psychotherapy $4 \%$ (more data available from the authors on request).

Our freedom of information request to the GMC was made in March 2009. There are a number of specialist registers for psychiatry and some doctors are on more than one, for example old age and general psychiatry registers. It was reported that 8433 doctors were registered as psychiatrists, out of a total of 119868 doctors on all specialist registers. Approximately, a further 120000 doctors are registered with the GMC but not as specialists.

There were 577171 specialist general practitioners (GPs). Psychiatrists therefore comprised $7.0 \%$ of all

\begin{tabular}{|c|c|c|c|c|}
\hline \multirow[b]{2}{*}{ Foundation school } & \multicolumn{2}{|c|}{$n$} & \multicolumn{2}{|c|}{$n(\%)$} \\
\hline & FY1 posts & FY2 posts & $\begin{array}{l}\text { FY1 posts } \\
\text { in psychiatry }\end{array}$ & $\begin{array}{l}\text { FY2 posts } \\
\text { in psychiatry }\end{array}$ \\
\hline $\begin{array}{l}\text { Birmingham } \\
\text { Black Country } \\
\text { Coventry and Warwick } \\
\text { Hereford and Worcestershire } \\
\text { Keele (Shropshire and Staffordshire) }\end{array}$ & 626 & 578 & $22(3.5)$ & $27(4.7)$ \\
\hline East Anglian & 287 & 287 & $3(1.0)$ & $26(9.1)$ \\
\hline Leicestershire, Northamptonshire and Rutland & 174 & 166 & $5(2.9)$ & $7(4.2)$ \\
\hline Mersey Deanery & 314 & 339 & $3(1.0)$ & $16(4.7)$ \\
\hline North Central Thames & 362 & 315 & $3(0.8)$ & $9(2.9)$ \\
\hline Trent & 297 & 294 & $8(2.7)$ & $9(3.1)$ \\
\hline North East Thames & 306 & 306 & $4(1.3)$ & $26(8.5)$ \\
\hline North West Thames & 299 & 282 & $2(0.7)$ & $12(4.3)$ \\
\hline North West & 561 & 561 & $15(2.7)$ & $19(3.4)$ \\
\hline North Yorkshire and East Coast & 181 & 157 & $12(6.6)$ & $12(7.6)$ \\
\hline Northern Deanery & 389 & 423 & $0(0)$ & $19(4.5)$ \\
\hline South Central (Oxford data missing) & 303 & 275 & $0(0)$ & $22(8.0)$ \\
\hline Severn & 299 & 263 & $3(1.0)$ & $18(6.8)$ \\
\hline South Thames & 874 & 808 & $16(1.8)$ & $32(4.0)$ \\
\hline Peninsula & 207 & 184 & $3(1.4)$ & $10(5.4)$ \\
\hline South Yorkshire & 180 & 189 & $15(8.3)$ & $18(9.5)$ \\
\hline West Yorkshire & 295 & 287 & $7(2.4)$ & $10(3.5)$ \\
\hline Total & 5954 & 5714 & $121(2.0)$ & $292(5.1)$ \\
\hline Grand total & \multicolumn{2}{|c|}{11668} & \multicolumn{2}{|c|}{413 (3.5) } \\
\hline
\end{tabular}

FY, foundation year. 


\begin{tabular}{lcc} 
Table 2 & $\begin{array}{l}\text { Higher and core training posts in schools of } \\
\text { psychiatry in 2008/2009 }\end{array}$ \\
$\begin{array}{l}\text { Higher training } \\
\text { posts, } n\end{array}$ & $\begin{array}{c}\text { Core training } \\
\text { posts, } n\end{array}$ \\
\hline East England & 128 & 129 \\
\hline Mersey & 60 & 60 \\
\hline Northern & 74 & 87 \\
\hline North Western & 110 & 123 \\
\hline Kent, Surrey, Sussex & 43 & 54 \\
\hline London & 492 & 462 \\
\hline Yorkshire and the Humber & 80 & 116 \\
\hline East Midlands & 47 & 90 \\
\hline Oxford & 100 & 62 \\
\hline South West Peninsula & 27 & 36 \\
\hline West Midlands & 102 & 163 \\
\hline Severn & 61 & 63 \\
\hline Wessex & 54 & 54 \\
\hline Total & $\mathbf{1 3 7 8}$ & $\mathbf{1 4 9 8}$
\end{tabular}

\begin{tabular}{llr} 
Table 3 & $\begin{array}{l}\text { Doctors on specialist General Medical Council } \\
\text { registers as of March 2009 }\end{array}$ \\
\hline All specialties & $n$ \\
\hline General practice (GP) & 119868 \\
\hline All non-GP specialties (including psychiatry) & 577171 \\
\hline Psychiatry & 62151 \\
\hline
\end{tabular}

registered specialists including GPs and $13.6 \%$ of all non-GP specialists (Table 3 ).

\section{Discussion}

Using our measure of success, namely the number of posts in psychiatry in the foundation programme, we found that our standard was substantially not met, which means that only a minority of foundation doctors (20\%) could expect to receive programmed training in psychiatry. Approximately 400 out of 12000 posts in the foundation schools in England are designated for psychiatric training. Assuming each post is of 4 months' duration (a conservative estimate as some posts are of 6 months' duration) there would need to be about 2000 posts in psychiatry (12000 divided by 6) to meet the standard (since each post can train three doctors per year and foundation training lasts 2 years). The index of success for psychiatry in the foundation schools in England therefore currently stands at $400 / 2000$ or 0.20 , that is, low. We would conclude therefore that the recently reformed postgraduate educational structures of the UK are not meeting the mental health training needs of newly qualified doctors.

However, this conclusion and the study on which it is based could be criticised on a number of levels. It might be argued that our data are unreliable or inaccurate. We would point to the high return rate (21 out of 22 schools) obtained directly from source. Furthermore, there is consistency with Department of Health workforce data gathered via trusts and strategic health authorities in England for a similar time frame, which found 290 foundation posts in psychiatry as of September 2009. ${ }^{7}$ At this time, aggregate information about the number of posts in particular specialties was not gathered by the UK foundation programme itself.

Second, it might be said that our measure of success, namely the number of posts in psychiatry in the foundation schools, is invalid in some way, partial or too crude. It could be argued, for instance, that most foundation doctors actually receive their foundation training in psychiatry and achieve mental health competences in a variety of ways outside of specialist posts via, for example, foundation 'tasters'. However, a clear negative finding of our survey was a lack of information about tasters. Although the new foundation programme reference guide recommends enhancing the role of 'tasters' to inform career choices, and a number of foundation programmes are looking towards Balint-type groups for their trainees, we know of no national initiative to provide training in psychiatry to foundation doctors by any means other than via training posts. Furthermore, to recommend that training in any specialty be delivered 'informally' or 'collaterally' to foundation doctors would be contrary to the founding principles of the foundation programme itself.

It might also be said that we set the standard too high, that psychiatry as a medical specialty is not of sufficient importance to society - or is simply not 'medical' enough to warrant a substantial place in a medical foundation programme, that is, at least one training post in psychiatry for each and every foundation doctor. This perspective is not supported by the levels of psychiatric morbidity and mortality that are regularly found among medical populations, ${ }^{8}$ including notably general practice and hospital patients. Psychiatry is not a small specialty as shown by our data on the numbers and proportions of UK specialist doctors registered with the GMC as psychiatrists $-13.6 \%$ of non-GP specialists, the same as anaesthetists. Furthermore, the foundation programme curriculum itself highlights mental health as an important domain of competency acquisition for all doctors.

Finally, it could be said that our sample is unrepresentative of the foundation programme as a whole since the programme is a UK-wide institution and we had access to only an English sample. Anecdotally, it appears that there may be proportionately more foundation posts in psychiatry in Northern Ireland and Scotland than England and possibly Wales. Historically, Northern Ireland and Scotland pursued a more active policy of converting core specialty posts into foundation training posts. It would be interesting to have more data on this, including the extent to which foundation doctors 'migrate' across national borders when they graduate to specialist training. However, although Northern Ireland and Scotland may constitute important exemplars that England would do well to note, it seems unlikely, due to their relatively small size, that they would substantially influence the overall UK picture.

All in all, therefore, we find our conclusion, that thus far psychiatry is substantially underrepresented in the 
foundation schools of the UK, to be sustained. The potential impact of what is in effect a 2-year psychiatry-free introduction to being a doctor is not the subject of further study or discussion here but is clearly of great concern. Recruitment to psychiatry, the professional standing of the specialty, the psychiatric knowledge and skills of all doctors, and the mental and physical well-being of patients as a whole are unlikely to be improved by this situation.

The data reported in the paper constituted part of the Royal College of Psychiatrists' presentation to Professor John Collins and his Expert Advisory Panel charged with reviewing the foundation programme. ${ }^{9}$ Their recommendations were extensive but included that the foundation programme curriculum should give greater emphasis to the total patient, longer-term conditions and community care. They also advised that increased flexibility in foundation posts should reflect trainee career choices, workforce needs, and increased community placements. There should be provision of careers information and advice and access to 'tasters' should be maximised. If widely implemented, these recommendations, and many others, should improve the position of psychiatry in the foundation programme.

\section{Appendix - Definitions of terms}

Foundation programme - the 2-year training programme for newly qualified doctors, completion of which is essential for progression to specialist training, as specified by Modernising Medical Careers. ${ }^{3}$

Foundation years 1 or 2 (FY1, FY2) - the first and second training years of a foundation programme.

Foundation trainee - an FY1 or FY2 trainee.

The Foundation Programme Office - central administrative body which oversees the delivery of the national foundation programme through the local foundation schools.

Core trainee - a doctor training on a core specialty programme, in this case psychiatry.

Higher trainee - a doctor undertaking a further 3 years of post-membership specialty training resulting in gaining their Certificate of Completion of Training (CCT).

Post - a training post, usually 4 months for foundation trainees, 6 months for core trainees, and 12 months for higher trainees (these durations were assumed in this study). The number of posts need not equal the number of trainees, and each post can train three, two or one trainee per year.

Foundation school - administrative unit organising recruitment and training of a number of local foundation programmes.

Training programme (core or higher) - an administrative unit, usually linked to an academic department, and one of several programmes in a school. (In some schools each trainee has a programme which consists of the posts they will do in their training; we have not used programme in that way in this paper.)

Tasters - up to 1 week of elective specialist experience available in the second foundation year designed to inform career choice. They would normally be taken in the first or possibly early in the second FY2 post, assuming 4-month duration of post.

\section{Acknowledgements}

We would like to thank Stuart Carney, Deputy Director of the Foundation Programme UK; Clare Oakley, Joanna Carroll and Robert Howard at the Royal College of Psychiatrists, the directors and administrators of the foundation schools and the heads of psychiatry schools and their administrators in England for their kind assistance and support.

\section{About the authors}

John Lowe, consultant in general adult psychiatry and college tutor, St Charles Hospital, Central and North West London NHS Foundation Trust, London, Gianetta Rands, consultant in general and old age psychiatry, Camden and Islington NHS Foundation Trust, honorary senior lecturer, Department of Mental Health Sciences, University College London, and training programme director for the UCL core psychiatry training programme, London Deanery (1999-2009).

\section{References}

1 Department of Health. Modernising Medical Careers. Department of Health 2009.

2 Foundation Programme UK. The Foundation Programme Curriculum. FP UK, 2007 (http://www.foundationprogramme.nhs.UK/pages/home/ key-documents \#foundation-programme-curriculum).

3 Herzberg J, Forrest A, Heard S. Modernising medical careers: an opportunity for psychiatry? Psychiatr Bull 2004; 28: 233-4.

4 Brown N, Bhugra D. Modernising medical careers, the Foundation Programme and psychiatry. Psychiatr Bull 2005; 29: 204-6.

5 Boyle AM, Chaloner DA, Millward T, Rao V, Messer C. Recruitment from foundation year 2 posts into specialty training: a potential success story? Psychiatr Bull 2009; 33: 306-8.

6 Department of Health. A Guide to Postgraduate Specialty Training in the UK (The Gold Guide). Department of Health, 2007.

7 NHS Information Centre for Health and Social Care. NHS Staff 1998 2008 (Medical and Dental). NHS ICHSC, March 2009 (http:// www.ic.nhs.uk/statistics-and-data-collections/workforce/nhs-staffnumbers/nhs-staff-1998-2008-medical-and-dental).

8 Academy of Medical Royal Colleges, Royal College of Psychiatrists. No Health without Mental Health: The Supporting Evidence. Academy of Medical Royal Colleges, 2009.

9 Collins J. Foundation for Excellence: An Evaluation of the Foundation Programme. Medical Education England, 2010 